\title{
Progress and prospects of medical education research in Asian Countries
}

\author{
Sultan Ayoub Meo ${ }^{1}$, Kamran Sattar', Chaudhary Habib ullah', \\ Sami Alnassar ${ }^{4}$, Waseem Hajjar ${ }^{5}$, Adnan Mahmood Usmani ${ }^{6}$
}

\begin{abstract}
Background and Objectives: Medical education has a profound impact on health care system. Progress in achieving medical education research goals varies over time and across countries. This study aimed to investigate the medical education research ambience in Asia during the period 1965-2015.

Methods: We investigated the bibliometric indicators of 49 Asian states in medical education research from 1965-2015. The data about Asian countries, their per capita GDP, expenditure on R\&D, universities and indexed scientific journals were collected. We recorded medical education related research documents published in Institute of Scientific Information (ISI) Web of Science, Thomson Reuters during the period 1965-2015.

Results: Asian countries collectively published 12721799 research articles, among them $40628(0.31 \%)$ publications were in medical education. China contributed total of 3351565 articles among which 5414 $(0.16 \%)$ research articles were in medical education; India added 1328725 papers with $4563(0.34 \%)$ in medical education; Japan produced 3080257 papers with $4199(0.13 \%)$ in medical education; Israel 561531 with $3848(0.68 \%)$ in medical education; and lastly, Georgia contributed a total of 296532 research articles with $2565(0.86 \%)$ in medical education.

Conclusions: In Asia, the top five countries in medical education research are China, Georgia, Israel, Japan and India. The countries at low ranking are Yemen, Palestine, Myanmar, Kazakhstan, Syria and Armenia. In Asian states, the overall performance in medical science research needs policies to enhance its impact globally. Medical universities should offer research programs for learning and understanding the challengeable issues in medical education research.
\end{abstract}

KEYWORDS: Asia, Medical education, Indexed journal, Research.

doi: https://doi.org/10.12669/pjms.35.6.1147

How to cite this:

Meo SA, Sattar K, Habib-Ullah C, Alnassar S, Hajjar W, Usmani AM. Progress and prospects of medical education research in Asian Countries. Pak J Med Sci. 2019;35(6):1475-1481. doi: https://doi.org/10.12669/pjms.35.6.1147

This is an Open Access article distributed under the terms of the Creative Commons Attribution License (http://creativecommons.org/licenses/by/3.0), which permits unrestricted use, distribution, and reproduction in any medium, provided the original work is properly cited.

\section{INTRODUCTION}

Asia is the largest and most populous continent on the globe with 4.40 billion people. ${ }^{1}$ Asia is marked by its history, multi-cultural traditions, geography, and vast social, economic and political diversity. ${ }^{1}$ The

\footnotetext{
Correspondence:

Prof. Sultan Ayoub Meo, MBBS, Ph.D, M Med Ed, FRCP.

Professor and Consultant in Clinical Physiology,

Department of Physiology, College of Medicine,

King Saud University, P.O. Box 2925, Riyadh 11461, Saudi Arabia.

Email: sultanmeo@hotmail.com / smeo@ksu.edu.sa

* Received for Publication:

May 26, 2019

* Revision Received:

* Revision Accepted:

August 24, 2019

August 26, 2019
}

pattern of health \& disease, and health care system in Asia is very diverse. ${ }^{2}$

A few Asian states are swiftly stirring to uphold a quality medical education and are giving ardent extraordinary consideration to nurturing higher education and research in the region. ${ }^{3}$ Medical education has a broader impact on medical teaching and clinical practice. The research in medical education and associated health sciences has a noteworthy contribution to the nation's monetary development with long-standing sustainable growth, and, ultimately, upgrading the health care system and living standard. ${ }^{4}$ To quantify the research progress of any nation, bibliometric measures including research documents and their 
visibility in global science are primary tools to comprehend growth and global extent. ${ }^{5}$

The research documents are strategic gauges for the development of nations and provide foundation for planned decisions for social and economic success. ${ }^{6,7}$ Asian states are fostering the promotion of education and research culture in the region. However, there is an acute lack of medical education research in the region. Therefore, the present study aimed to investigate the medical education research ambience in Asia during the period 1965-2015.

\section{METHODS}

For the present study, we reviewed the data base literature in the month of June 2018 on "medical education" theme in Asian countries. We examined 49 Asian countries listed as per United Nations. ${ }^{8}$ The data about Asian countries, their per capita GDP, expenditure on research and development (R\&D), universities and indexed scientific journals were recorded. Medical education allied studies on health professions exploring various aspects in teaching, learning, curriculum, admissions and assessment were collected. The articles including original articles, reviews, editorials, letters to editors published in Institute of Scientific Information (ISI) Web of Science, Thomson Reuters during the period 1965-2015 were recorded and analyzed. ${ }^{9}$ We excluded 10 Asian countries, which produced less than 25 research articles in medical education during the period 1965-2015, and finally, 39 Asian states were selected.

The information about the number of universities was recorded from the World Association of Universities. ${ }^{10}$ The details about medical and allied health science schools were recorded from websites of the concerned country and licensed organizations. We used the Web of Science for evaluating the ISI indexed journals. The country was selected, the individual Asian state appellation e.g. "China, Saudi Arabia, Pakistan, India, Israel, Malaysia" etc, was entered and the information of detailed journals along with the impact factors for each journal was retrieved from the Journal Citation Report, Institute of Scientific Information (ISI) Web of Science, Thomson Reuters. ${ }^{9}$ For the recording of research documents in "medical education" in global scientific journals indexed in ISI Web of Science, a particular country was selected, subject field "Medical Education" was entered and comprehensive information about number of research papers, total citations, citations per document ${ }^{9}$ and Hirsch Index ( $h$-index) in medical education was obtained.
Ethical statement: Ethical approval was not obtained as humans or animals were not involved. We acquired data based literature on medical education in Asian countries.

Statistical Analysis: Statistical Package for the Social Sciences (SPSS) Inc Chicago, IL, USA, software version 21 was used to analyze the data. The results were presented as Mean \pm Standard Error of Mean (SEM). The Pearson correlation coefficient was used to find the strength of relation between different variables. $p$-value $<0.05$ was considered significant.

\section{RESULTS}

In Asian states, the total number of universities and degree awarding institutes are 3444 with an average number of 88.30 per country. There are a total 1051 ISI indexed scientific journals (mean 26.95). The sum of their GDP is $\$ 509120.98$ (mean $\$ 13054.38$ ) and the mean R\&D spending of Asian countries is $0.67 \%$ (Table-I).

The total number of research articles published from Asian countries in ISI indexed journals during the period 1965-2015 are 12721799 (mean 326199.97), total number of publications in medical education are 40628 (mean 1041.74), citations 438634 (mean 11247.02), citations per documents 9.39, Hirsch Index ( $h$-index) 1337 (mean 34.30) (Table-II).

Based on research documents published in medical education in ISI-Web of science, the top five Asian countries are China contributing 5414, India contributing 4563, Japan 4199, Israel 3848 and Georgia with 2565 research papers in Medical Education (Fig.1). However, based on Hirsch Index ( $h$-Index) in medical education, the ranking of Asian countries is: Georgia (101), Israel (98), China (89), Japan (81) and India (76) (Fig.1). While considering the percentage of medical education documents in

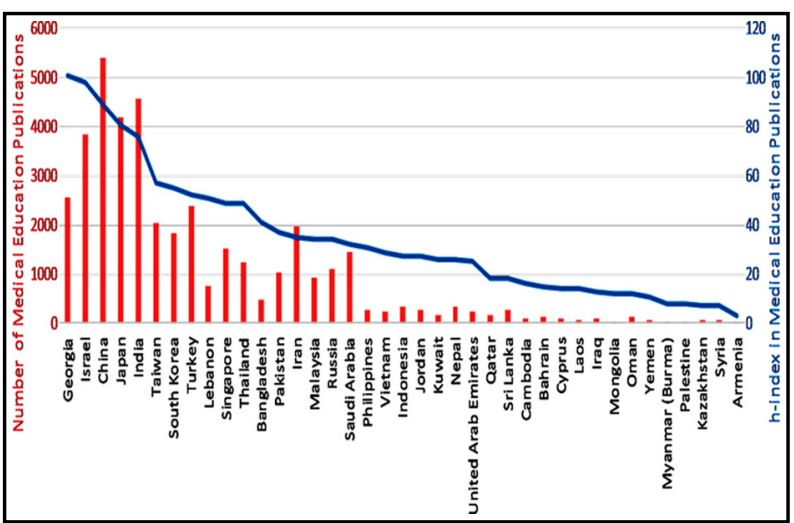

Fig.1: Total number of publications in medical education in ISI web of science and Herish Index of Asian countries in medical education during the period 1965-2015. 
Table-I: Number of universities, medical schools, ISI Indexed journals, GDP and spending on R\&D of Asian countries during the period 1965-2015.

\begin{tabular}{|c|c|c|c|c|c|}
\hline Country & $\begin{array}{c}\text { No. of } \\
\text { Iniversities }\end{array}$ & $\begin{array}{c}\text { No. of } \\
\text { Medical } \\
\text { Schools }\end{array}$ & $\begin{array}{c}\text { No. of } \\
\text { ISI Indexed } \\
\text { journals }\end{array}$ & $G D P$ & $R \mathcal{R E D}$ \\
\hline Georgia & 13 & 12 & 1 & 2699 & 0.2 \\
\hline Israel & 22 & 5 & 12 & 27341 & 4.14 \\
\hline China & 389 & 132 & 173 & 3938 & 1.42 \\
\hline Japan & 567 & 85 & 235 & 40101 & 3.28 \\
\hline India & 367 & 346 & 100 & 1215 & 0.8 \\
\hline Taiwan & 86 & 12 & 34 & 32316 & 2.33 \\
\hline South Korea & 146 & 42 & 103 & 20108 & 3 \\
\hline Turkey & 92 & 78 & 53 & 9729 & 0.7 \\
\hline Lebanon & 24 & 5 & 0 & 8146 & 0.3 \\
\hline Singapore & 6 & 3 & 52 & 38935 & 2.12 \\
\hline Thailand & 67 & 18 & 8 & 4211 & 0.26 \\
\hline Bangladesh & 80 & 70 & 4 & 608 & 0.4 \\
\hline Pakistan & 189 & 156 & 12 & 1002 & 0.41 \\
\hline Iran & 197 & 60 & 44 & 4403 & 0.62 \\
\hline Malaysia & 146 & 26 & 10 & 7987 & 0.82 \\
\hline Russia & 316 & 83 & 147 & 12736 & 1.14 \\
\hline Saudi Arabia & a 64 & 30 & 10 & 16862 & 0.13 \\
\hline Philippines & 117 & 44 & 4 & 1991 & 0.12 \\
\hline Vietnam & 46 & 13 & 0 & 1136 & 0.18 \\
\hline Indonesia & 181 & 74 & 0 & 2550 & 0.1 \\
\hline Jordan & 30 & 5 & 1 & 3976 & 0.39 \\
\hline Kuwait & 8 & 1 & 5 & 50567 & 0.13 \\
\hline Nepal & 8 & 21 & 1 & 478 & 0.21 \\
\hline UAE & 36 & 6 & 38 & 44544 & 0.49 \\
\hline Qatar & 2 & 2 & 0 & 75176 & 0.47 \\
\hline Sri Lanka & 25 & 9 & 1 & 2184 & 0.15 \\
\hline Cambodia & 20 & 3 & 0 & 764 & 0.1 \\
\hline Bahrain & 12 & 4 & 1 & 18868 & 0.04 \\
\hline Cyprus & 16 & 5 & 0 & 29733 & 0.37 \\
\hline Laos & 2 & 1 & 0 & 1661 & 0.04 \\
\hline Iraq & 48 & 23 & 0 & 2582 & 0.04 \\
\hline Mongolia & 10 & 7 & 0 & 2144 & 0.25 \\
\hline Oman & 11 & 2 & 0 & 20524 & 0.17 \\
\hline Yemen & 14 & 6 & 0 & 1181 & 0.11 \\
\hline Myanmar (B) & B) 34 & 13 & 0 & 1204 & 0.12 \\
\hline Palestine & 16 & 5 & 0 & 1194 & 0.1 \\
\hline Kazakhstan & 28 & 8 & 0 & 8553 & 0.21 \\
\hline Syria & 15 & 7 & 0 & 2590 & 0.2 \\
\hline Armenia & 12 & 5 & 3 & 3184 & 0.24 \\
\hline Total & 3444 & 1365 & 10515 & 509120.98 & 26.3 \\
\hline Mean & 88.30 & 35 & 26.94 & 13054.38 & 0.67 \\
\hline SEM & 20.28 & 9.79 & 8.68 & 2772.44 & 0.12 \\
\hline
\end{tabular}

The data were recorded from ISI-web of Science, $2017 .{ }^{9}$ Note: GDP and R\&D spending is presented in a mean. total research documents in a particular country, Georgia had $0.86 \%$, Israel $0.68 \%$, India $0.34 \%$, China $0.16 \%$ and Japan $0.13 \%$ (Table-II). The percentage of medical education documents in comparison to total number of medical education research documents in entire Asia was: China 13\%, India 11\%, Japan 10\%, Israel 9\%, Georgia and Turkey $6 \%$ each (Fig.2).

We established the Pearson correlation coefficient and a positive association was observed between medical schools and total number of research articles appearing in ISI Web of Science $\left(r^{2}=0.458, p=0.003\right)$. Similar observation was also found between the number of medical schools and research appearing in the area of medical education $\left(r^{2}=0.541, p=0.0001\right)$ (Fig.3).

\section{DISCUSSION}

Medical education research has a profound impact on the health care system. ${ }^{3}$ In Asia, the top five countries in medical education research are China, Georgia, Israel, Japan and India. On the other hand, countries at low ranking are Yemen, Palestine, Myanmar, Kazakhstan, Syria and Armenia. In Asian countries, the medical education system shows marked diversity depending on the social, cultural and educational methods. Few Asian countries are trying to enhance research in medical education.,11

Majumder ${ }^{12}$ reported that medical education in Asia is not a need-based education, since bureaucrats under the influence of international donor agencies make major decisions and most of the decisions are based on political and financial interest, deliberately ignoring the relevance of medical education research. The present study findings agree with Majumder ${ }^{12}$ that in Asian countries currently there are 3444 universities and among them, 1365 are medical universities (Table-I), but not a single one of them flourished and achieved a standing like US or European universities to be a flagship medical education institute.

As per Shanghai ranking of the world universities 2017'3, America has 16 and Europe has four universities among the top 20 universities. However, none of the Asian universities achieved the ranking among the top 20 universities. ${ }^{13}$ Moreover, among top 100 universities, America has 52 universities; Europe has 35; and Asia has 13 universities in medical and health sciences. ${ }^{13}$ This reflects the poor performance of Asian universities in global research production.

In the present study, we found that very few Asian states have produced research in medical education. Asian countries such as China, Georgia, 
Table-II: Number of research documents published in Medical Education in ISI web of science, total citations, citations per document, Herish Index and overall ranking of Asian countries in Medical Education during the period 1965-2015.

\begin{tabular}{|c|c|c|c|c|c|c|}
\hline Country & $\begin{array}{c}\text { Total } \\
\text { publications }\end{array}$ & $\begin{array}{c}\text { Total Medical } \\
\text { Education } \\
\text { publications \& \% }\end{array}$ & $\begin{array}{c}\text { Total } \\
\text { Citations }\end{array}$ & $\begin{array}{c}\text { Citations } \\
\text { per } \\
\text { Document }\end{array}$ & $\begin{array}{c}\text { H Index } \\
\text { based on Medical } \\
\text { Education }\end{array}$ & $\begin{array}{c}\text { Country Ranking } \\
\text { in Medical } \\
\text { Education }\end{array}$ \\
\hline Georgia & 296532 & $2565(0.86 \%)$ & 52874 & 20.61 & 101 & 1 \\
\hline Israel & 561531 & $3848(0.68 \%)$ & 66932 & 17.39 & 98 & 2 \\
\hline China & 3351565 & $5414(0.16 \%)$ & 61384 & 11.34 & 89 & 3 \\
\hline Japan & 3080257 & 4199 (0.13\%) & 42541 & 10.13 & 81 & 4 \\
\hline India & 1328725 & $4563(0.34 \%)$ & 39906 & 8.75 & 76 & 5 \\
\hline Taiwan & 532496 & $2044(0.38 \%)$ & 20494 & 10 & 57 & 6 \\
\hline South Korea & 812407 & $1832(0.22 \%)$ & 17932 & 10 & 55 & 7 \\
\hline Turkey & 467872 & $2403(0.51 \%)$ & 19016 & 8 & 52 & 8 \\
\hline Lebanon & 44953 & $750(1.66 \%)$ & 12991 & 17 & 51 & 9 \\
\hline Singapore & 215698 & $1514(0.70 \%)$ & 13658 & 9 & 49 & 10 \\
\hline Thailand & 127908 & $1256(0.98 \%)$ & 12576 & 10 & 49 & 11 \\
\hline Bangladesh & 30447 & $467(1.53 \%)$ & 8471 & 18.14 & 41 & 12 \\
\hline Pakistan & 89891 & $1043(1.16 \%)$ & 9740 & 9.34 & 37 & 13 \\
\hline Iran & 322322 & $1971(0.61 \%)$ & 9261 & 4.7 & 35 & 14 \\
\hline Malaysia & 150331 & $946(0.62 \%)$ & 6258 & 6.62 & 34 & 15 \\
\hline Russia & 861873 & $1111(0.12 \%)$ & 5052 & 5 & 34 & 16 \\
\hline Saudi Arabia & 126521 & $1450(1.14 \%)$ & 7394 & 5 & 32 & 17 \\
\hline Philippines & 26588 & $271(1.01 \%)$ & 4906 & 18 & 31 & 18 \\
\hline Vietnam & 30571 & $245(0.80 \%)$ & 2701 & 11 & 29 & 19 \\
\hline Indonesia & 39225 & $334(0.87)$ & 3030 & 8.81 & 27 & 20 \\
\hline Jordan & 32798 & $278(0.84 \%)$ & 4583 & 16 & 27 & 21 \\
\hline Kuwait & 22570 & $185(0.81 \%)$ & 2341 & 13 & 26 & 22 \\
\hline Nepal & 10776 & $354(3.28 \%)$ & 3082 & 9 & 26 & 23 \\
\hline UAE & 15017 & $223(1.55 \%)$ & 2180 & 10 & 25 & 24 \\
\hline Sri Lanka & 15400 & $285(1.85 \%)$ & 1618 & 6 & 18 & 25 \\
\hline Qatar & 14505 & $180(1.24 \%)$ & 1150 & 6 & 18 & 26 \\
\hline Cambodia & 2671 & $8(3.10 \%)$ & 804 & 9.69 & 16 & 27 \\
\hline Bahrain & 4486 & $123(2.74 \%)$ & 913 & 7 & 15 & 28 \\
\hline Cyprus & 18466 & $108(0.58 \%)$ & 1111 & 10.29 & 14 & 29 \\
\hline Laos & 1720 & $58(0.04 \%)$ & 645 & 11.12 & 14 & 30 \\
\hline Iraq & 14317 & $83(0.57 \%)$ & 740 & 8.92 & 13 & 31 \\
\hline Mongolia & 14081 & $48(0.34 \%)$ & 356 & 7 & 12 & 32 \\
\hline Oman & 11855 & $134(1.13 \%)$ & 807 & 6 & 12 & 33 \\
\hline Yemen & 2913 & $58(1.99 \%)$ & 378 & 7 & 11 & 34 \\
\hline Palestine & 2054 & $34(1.65 \%)$ & 257 & 8 & 8 & 35 \\
\hline Myanmar & 1475 & $34(2.30 \%)$ & 171 & 5.03 & 8 & 36 \\
\hline Kazakhstan & 15167 & $60(0.39 \%)$ & 133 & 2.22 & 7 & 37 \\
\hline Syria & 6087 & $49(0.80 \%)$ & 199 & 4 & 7 & 38 \\
\hline Armenia & 17728 & $25(0.14 \%)$ & 49 & 1.764 & 3 & 39 \\
\hline Total & 12721799 & $40628(0.31 \%)$ & 438634 & 366.414 & 1337 & $\mathrm{~N} / \mathrm{A}$ \\
\hline Mean & 326199.97 & $1041.74(0.31 \%)$ & 11247.02 & 9.39 & 34.30 & $\mathrm{~N} / \mathrm{A}$ \\
\hline SEM & 120092.56 & 210.63 & 2123.68 & 0.625 & 3.40 & \\
\hline
\end{tabular}

The data were recorded from ISI-web of Science, 2017.9

Japan and Israel have developed educational policies and collaborated with highly reputable institutes of postgraduate excellence. Israel increased emphasis on education and research in both basic and clinical medical sciences and education. The medical educational tools are interactive and learner-centered rather than being frontal teaching formats. ${ }^{14}$ In Israel, there are
22 universities, 12 medical schools, and it has 12 ISI Indexed journals (Table-I). As per Shanghai Ranking 2017'3, Israel has five universities and degree awarding institutes within the top 500 universities (Fig.4). Israel produced 561531 research articles and among them, 3848 research articles are in medical education with h-index of 98. As per World Bank report, Israel is spending 


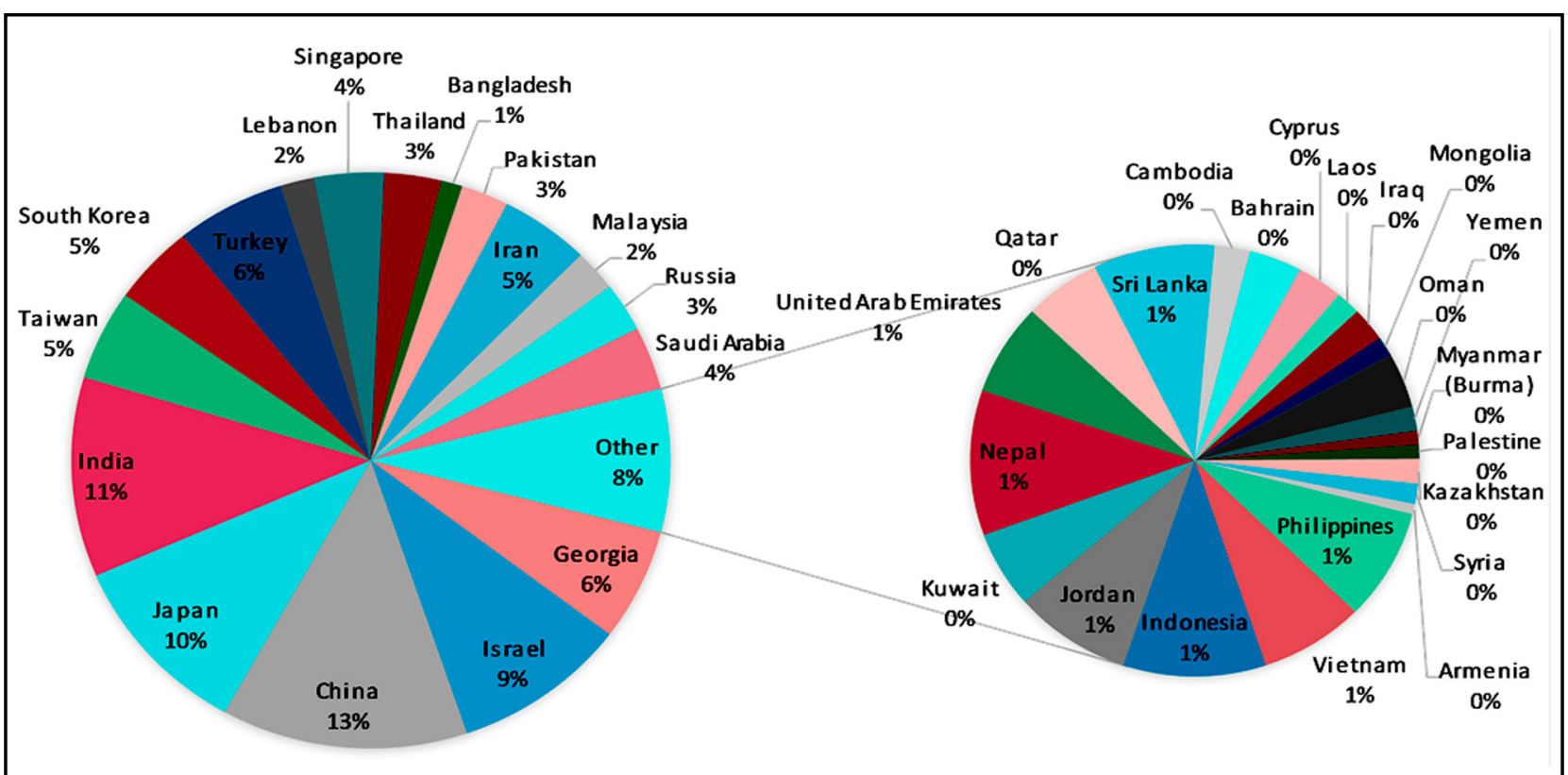

Fig.2: Asian countries contribution in medical education research published in ISI web of science during the period 1965-2015.

$4.41 \%$ of their GDP on R\&D which is the highest in the world ${ }^{15}$ and has highly ranked universities. These are the main reasons that Israel is ranked $2^{\text {nd }}$ in Asian states in medical education research (Table-I and II).

China has a population of approximately 1.3 billion, occupying a huge diverse landmass and making a rapid transition from a Third-World to a First-World economy. ${ }^{16}$ China has 389 universities, 132 medical schools, 173 ISI indexed journals, and is spending $1.42 \%$ of their GDP on R\&D (Table-I). It also has 45 Universities among the top 500 universities. ${ }^{13}$ China is contributing a

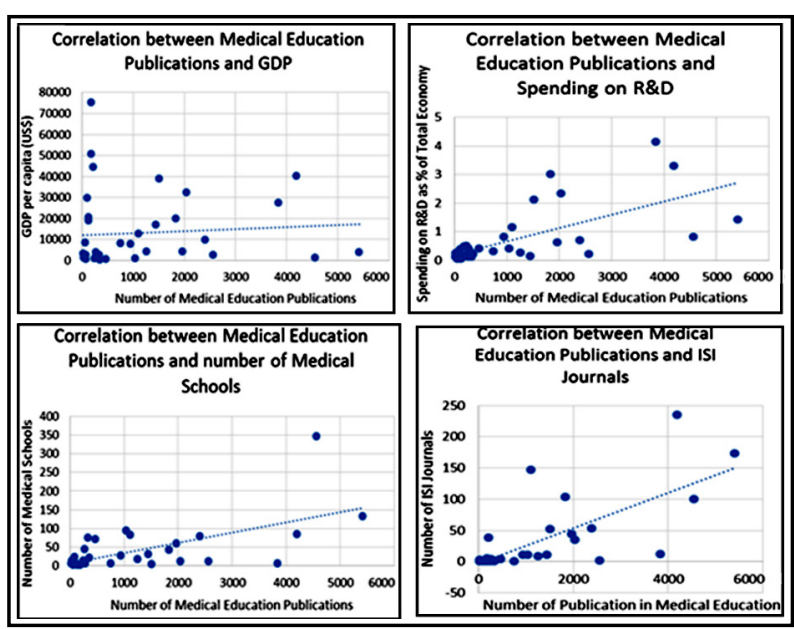

Fig.3: Correlation between number of publications in medical education with GDP, spending on R\&D, number of medical schools and ISI indexed journals. significant amount of research articles in ISI Web of Science (3351565), medical education (5414), h-index (89) and is currently holding third place in research in medical education among the Asian countries (Table-II).

China has been moving fast, funding enormously with a swift growing science skilled personnel. However, Chinese research has to develop strategies to further enhance its impact, which the country is trying to address. China is trying to increase research funding to $2.5 \%$ of the country's GDP by 2020. One area in which the country is

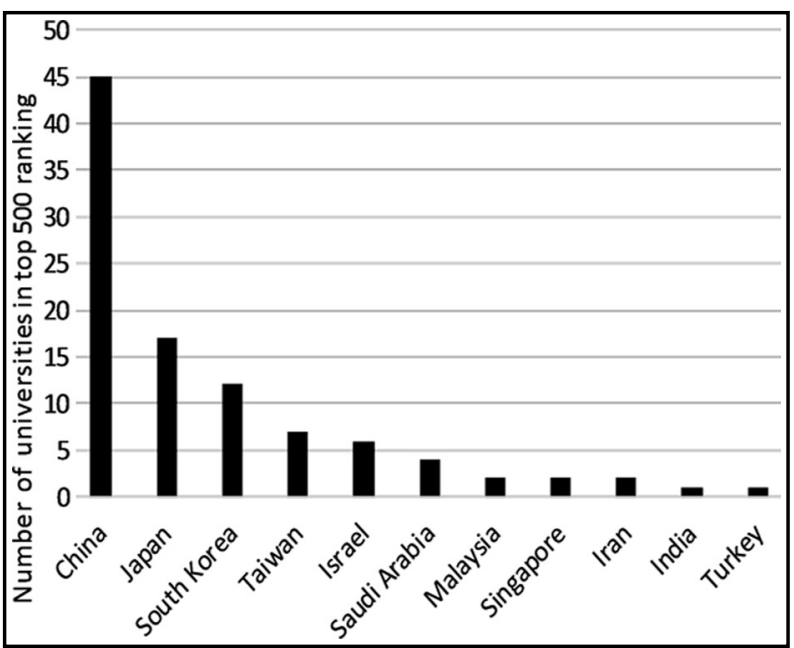

Fig.4: Top 500 universities in Asian countries (Academic Ranking of World Universities Shanghai Ranking Report-2017) ${ }^{13}$ 
competing globally is molecular medicine, and desires to dominate precision medicine. The world is observing China racing forward, but it still has a long way to go before it becomes a leader in medical education research and innovation. ${ }^{16}$

India has 367 universities, 346 medical schools, 100 ISI indexed journals, and has published 1328725 research articles, among which 4563 are in medical education with h-index of 76 . As per our study findings, among Asian countries, India is standing among the top five countries in medical education. Despite its huge size and population of about 1.3 billion people, the number of universities and research institutes and their outcome has not been satisfactory. Indian universities and their research are mired in bureaucracy and insufficient funding, being less than $0.9 \%$ of the GDP since 2005 . All these factors have muted the spirit of academic excellence and hampered research ${ }^{17}$ especially in medical education. The other Asian countries attempting to enhance research in medical education are Taiwan, South Korea, Turkey, Malaysia, Pakistan, and oil rich Gulf Cooperation Council (GCC) states.

In Pakistan, there is an increasing appreciation towards establishing medical education departments and postgraduate degree programs in medical and dental schools. However, the infrastructure, availability of trained faculty and financial resources are serious issues. Majority of the medical schools do not have a full time qualified medical education faculty. The Higher Education Commission (HEC) and Pakistan Medical and Dental Council (PMDC) should provide policy to strengthen the medical education and its allied research in the country. ${ }^{18}$

The GCC countries are constantly increasing their spending on education and research funding. The educational budget of Saudi Arabia reached $\$ 54.54$ billion for the year $2015 .{ }^{19}$ GCC universities are trying to establish an international alliance to promote research culture. However, the research outcome in medical education from GCC states is still marginalized. ${ }^{3}$

Hamdy et al. ${ }^{20}$ reported that in Asia, GCC states are in a major social, cultural and fiscal transformation. However, in the region, the progress of medical education is relatively newfangled. Medical schools' curricula are variable without integration, and there are faculty shortages, lack of training facilities and faculty development in medical education. In concurrent to the findings of Hamdy et al., ${ }^{20}$ we believe that these are the reasons that in
Asian states, the wealthy GCC nations have not produced a significant volume of research in medical education.

In another study, Khalid $\mathrm{BA}^{21}$ demonstrated that in GCC states, medical universities are changing their curricula to maintain efficiency. Many medical schools followed the traditional curriculum, while a few followed a hybrid problem-based learning (PBL) curricula. Even with the curriculum transformation, GCC states produced little research in medical education. In another study, Khalid Abdulrehman $^{22}$ reported that several factors obstruct medical education research in the region including lack of medical education research funding, absence of biomedical industries interest in medical education research, lack of research skills, and dearth of regional peer-reviewed ISI indexed journals in medical education.

Choung and Hwang ${ }^{23}$ reported that universities play an essential role in increasing number of research articles in the ISI database. In Asian countries, the total numbers of universities are 3444, from which 365 are medical universities or colleges. In the present study, we found that since the number of universities increased, number of research papers also increased. Meo et al. ${ }^{24}$ found that states with a vast number of universities produced more research articles. Congruently, in this study, we found that Asian states which increased the number of universities showed better research outcome in medical education.

Limitations of the study: The strengths of this study are that we searched the research performance of Asian countries from very reliable sources which include Institute of Scientific Information (ISI) Web of Science, Journal Citation Reports (Thomson Reuters) and World Bank. A comprehensive search of the literature would undoubtedly enrich the framework of available strategies for identification of ambience. However, our study had a few limitations. Occasionally, citation count tools may mis-cite or re-cite a paper, which may inflate the number of documents or citation sums. We also excluded 10 Asian countries that produced less than 25 research articles in medical education.

\section{CONCLUSION}

In Asia, the top five countries in medical education research are China, Georgia, Israel, Japan and India. However, the countries at the bottom line ranking are Yemen, Palestine, Myanmar, Kazakhstan, Syria and Armenia. A multidimensional approach is 
required to improve medical education research in Asian countries, and international alliances with universities and research rich institutes should be established to enhance research and its visibility.

Recommendations: Medical universities should offer compulsory research programs and research elective for their graduation which would provide the foundation for a durable approach to learning and understanding the challengeable issues in medical education research.

Acknowledgement: The authors are thankful to the Deanship of Scientific Research, King Saud University, Riyadh, Saudi Arabia for supporting the work through the research group project (RGP-181).

Declaration of interests: Authors declared no conflict of interests.

\section{REFERENCES}

1. Countries by continent, one world nations online. Available at: http://www.nationsonline.org/oneworld/asia.htm, Accessed: Nov 22, 2018.

2. Liu GG, Eggleston K, Hu TW. Emerging health economics and outcomes research in the Asia-Pacific region. Value Health. 2008;11(Suppl1):S1-S2. doi: 10.1111/j.15244733.2008.00360.x

3. Meo SA, Hassan A, Aqil M, Usmani AM. Medical education research in GCC countries. BMC Med Educ. 2015;15:8. doi 10.1186/s12909-015-0293-6

4. Meo SA, Usmani AM, Vohra MS, Bukhari IA. Impact of GDP, Spending on R\&D, number of universities and scientific journals on research publications in pharmacological sciences in Middle East. Eur Rev Med Pharmacol Sci. 2013;17:2697-2705.

5. Durieux V, Gevenois PA. Bibliometric indicators: quality measurements of scientific publication. Radiology. 2010;255:342-351. doi: 10.1148/radiol.09090626

6. Preis T, Moat HS, Stanley HE. Quantifying the Advantage of Looking Forward. Sci Rep. 2012;2(350):1-2. doi: 10.1038/ srep00350

7. Macilwain C. What science is really worth? Nature News. 2010;465:682-684. doi: $10.1038 / 465682 a$

8. United Nations: Geographical region and composition. Available at: http://unstats.un.org/unsd/methods/m49/ m49regin.htm\#asia. Accessed Dec 22, 2018.

9. Journal citation report, ISI web of Knowledge. Available at: http:/ / webofknowledge.com/JCR/JCR?PointOfEntry=Ho me\&SID=4FeKpokbnHkLlmE1OGe. Accessed: Dec 2, 2017.

10. International association of universities, the list of universities of the world. Available at: in http://www.iauaiu.net/content/list-heis. Accessed: Dec 8, 2018.

11. Mendis L, Adkoli BV, Adhikari RK, Huq MM, Qureshi AF. Postgraduate medical education in South Asia. BMJ. 2004;328(7443):779. doi: 10.1136/bmj.328.7443.779

12. Majumder MA. Issues and priorities of medical education research in Asia. Ann Acad Med Singapore. 2004;33:257-263.
13. Academic ranking of world universities, statistics by region Available at: http://www.shanghairanking.com/ARWUFIELD-Statistics-2016.html. Accessed: June 20, 2017.

14. Reis S, Urkin J, Nave R, Ber R, Ziv A, Miller OK, et al. Medical education in Israel 2016: Five medical schools in a period of transition. Israel J Health Policy Res. 2016;(45):5.

15. Word Bank. Available at: http://data.worldbank.org/ indicator/GB.XPD.RSDV.GD.ZS, Accessed: June 25, 2018.

16. Science in China. Nature news. 2016;534:451. doi: 10.1038/534451a

17. Padma TV. India's science test, Nature 2015; 521(7551): 1447. doi: $10.1038 / 521144 a$

18. Latif MZ, Wajid G. Reforming Medical Education in Pakistan through strengthening Departments of Medical Education. Pak J Med Sci. 2018;34(6):1439-1444. doi: 10.12669/ pjms.346.15942

19. Meo SA. Saudi Arabia: A future regional hub for advanced education, research, science and technology. J Pak Med Assoc. 2015;65(10):1112-1115.

20. Hamdy H, Telmesani AW, Al Wardy N, Abdel-Khalek N, Carruthers G, Hassan F, et al. Undergraduate medical education in the Gulf Cooperation Council: a multicountries study (Part 1). Med Teach. 2010;32:219-224. doi: 10.3109/01421590903389108

21. Khalid BA. The current status of medical education in the Gulf Cooperation Council countries. Ann Saudi Med. 2008;28:83-88. doi: 10.5144/0256-4947.2008.83

22. Bin Abdulrahman KA. The value of medical education research in Saudi Arabia. Med Teach. 2012;34(Suppl 1):S1S3. doi: 10.3109/0142159X.2012.661897

23. Choung JY, Hwang HR. National systems of innovation: Institutional linkages and performances in the case of Korea and Taiwan. Scientometrics. 2000;48:413-426.

24. Meo SA, Abeer Al Masri A, Usmani AM, Memon AN, Zaidi SZ. Impact of GDP, Spending on R\&D, Number of Universities and Scientific Journals on Research Publications among Asian Countries. PLOS ONE. 2013;8(6):e66449. doi: 10.1371/journal.pone.0066449

\section{Authors' Contribution:}

SAM contributed to the study design, literature review, analysis and interpretation of data and writing the manuscript. Takes responsibility of integrity of research.

KS, CH, SA, WH and AMU were involved in literature review and data analysis.

All authors have read and approved the manuscript.

Authors:

1. Sultan Ayoub Meo, MBBS, PhD. Department of Physiology,

2. Kamran Sattar, MBBS, M Med Ed. Medical Education,

3. Chaudhary Habib ullah, MBBS, FCPS. Orthopedic Surgery,

4. Sami Alnassar, MD, FRCS. Thoracic Surgery,

5. Waseem Hajjar, MD, FRCS. Thoracic Surgery,

6. Adnan Mahmood Usmani, MA, MCSE. University Diabetes Centre,

1-6: College of Medicine, King Saud University, Riyadh, Saudi Arabia. 